\title{
A Novel Technique for Correction of Bottoming Out Following Inferior Pedicle Breast Reduction
}

\author{
MOHAMED FARAG, M.D.; EMAN YAHYA SADEK, M.D. and AHMAD ALI, M.D. \\ The Department of Plastic Surgery, Faculty of Medicine, Ain Shams University
}

\begin{abstract}
Introduction: Bottoming out is a frequent pitfall of breast reduction following inferior pedicle technique. This is attributed to the lack of deep tissue suspension and skin envelope relaxation. The condition is associated with lack of medial fullness and poor projection. The authors present a new technique that depends on redistribution and auto-augmentation rather than resection of tissues.

Patients and Methods: The technique was performed in 25 patients who had bottoming out following inferior pedicle breast reduction. The time elapsed from the primary surgery to the corrective surgery ranged from 2 to 4.5 years with a mean of 2.5 years. The used technique consists of deepithelialization and complete division of the lower segment at the infra-mammary fold. The divided lower dermoglandular segment is rolled in a retromammary pocket underneath the pedicle and fixed to the pectoral fascia. The idea is to use this lower segment of the inferior pedicle as an auto-prosthesis. Follow-up period is 12 months.
\end{abstract}

Results: All patients achieved good breast shape with good projection. There were no serious complications. Only two patients developed partial wound disruption.

Conclusion: A novel technique for correction of bottoming out following inferior pedicle breast reduction was used with good surgical outcome.

Key Words: Bottoming out-Breast reduction.

\section{INTRODUCTION}

Bottoming out is a frequent pitfall of breast reduction [1]. It may occur after certain techniques of breast reduction especially the inferior pedicle technique. This deformity is characterised by overriding nipple and pseudo-ptosis. The nipple is at or above the infra-mammary fold. Chalekson et al., evaluated bottoming-out or pseudoptosis with ratios that were obtained from the sternal notch to the visual inferior pole of the breast [3]. Small et al., 2010 studied the anatomical surface measurements and the volumetric changes after breast reduction using 3D photography. Changes in anatomical surface measurements support the signif- icant volumetric changes seen in the first year. As total breast volume decreases, breast surface measurements should concurrently decrease while vector distances are stagnant. Three-dimensional longterm volumetric evaluation emphasized postoperative pseudo-ptosis with a $7 \%$ redistribution of tissue to the inferior pole of the breast [4].

Breast reduction techniques which depend on skin brassiere to maintain the shape tend to cause bottoming-out of the breast [5]. Rohrich et al., 2006 stated that the inverted-T inferior pedicle technique leads to a greater degree of bottoming-out or pseudoptosis [6]. The real causes of bottoming out are stretch of the inferior skin envelope, long scar lines, lack of parenchymal support, lateral displacement of the pedicle, and sagging of the lower pole which is the inferior pedicle by gravity effect. It is usually associated with empty upper pole. The inferior pedicle technique attempts to raise the inferior breast tissue superiorly while basing it inferiorly, thus involving two opposing vectors. As a result, the nipple-areola complex ultimately rides higher on the breast tissue than desired and leads to a poor cosmetic result. On the other hand, certain techniques of breast reduction are less liable to induce bottoming out [3,7-11].

Modifications of breast reduction techniques have been evolved to avoid bottoming out [19-27]. They include; internal suspension of the pedicle with sutures, dermal flaps, and others. The use of mesh as an internal brassiere to support the pedicle has been pioneered by Goés, who has shown that long-lasting aesthetic results can be obtained [2831]. Brown et al., 2010 used acellular dermal matrix internal brassiere to preventing the "bottoming out" in inferior pedicle breast reduction [12].

Keck et al., 2007 mentioned that the majority of post-operative changes take place during the first three months after surgery [18]. Brown et al., 
2010 stated that postoperative pseudoptosis can develop as early as few months postoperatively and continue to worsen over time as the skin envelope continues to stretch secondary to gravity and the weight of the breast parenchyma [12]. Small et al., 2010 demonstrated that significant volumetric surface measurement changes continue to occur during the first year following surgery. They attributed this finding to the breast tissue settling into the breast envelope as well as the resolution of post-operative edema [4].

Correction of post-reduction bottoming out of the breast is considered a challenge to breast surgeons. Techniques varied from repositioning of NAC, wedge resection of lower pole, tissue expansion-implant in upper pole $[\mathbf{1 3 , 1 4 , 1 5 ]}$. Hudson and Skoll 1991 suggested an algorithm for this problem. In case of pseudoptosis and the nipple does not require transposition, a simple inferior wedge excision could be done safely, regardless of the pedicle used in the initial surgery. If the nipple has to be transposed, the blood supply of nipple-areola complex must be carefully considered. The initial pedicle should be reused if it is known. Otherwise, a free nipple graft is perhaps the safest path to follow [16].

Our aim in this study is to present a new technique which can be used safely in correction of bottoming out deformity after inferior pedicle reduction mammaplasty. This technique depends on redistribution rather than resection of tissues.

\section{PATIENTS AND METHODS}

The study was conducted between May 2009 and December 2011. It involved 25 patients who have had bottoming out of the breast following variable period of breast reduction surgery. All patients had reduction mammaplasty using inferior pedicle technique and inverted T-scar. The age of patients ranged from 22 to 48 years old with a mean age of 33.5 years. The time elapsed from primary surgery to the corrective surgery ranged from 2 to 4.5 years with a mean of 2.5 years. The study was conducted in Ain Shams University Hospitals, Cairo, Egypt and Jeddah National Hospital, Jeddah, Saudi Arabia.

Markings and measurements were done while the patient is standing. The distance to the NAC from the midclavicular point and the distance to the NAC from inframammary fold (IMF) were measured (Fig. 1A). Elliptical marking was drawn to surround the transverse limb of the inverted Tscar (Fig. 1B). The maximum width of the elliptical marking at the center was determined regarding that at least $5 \mathrm{~cm}$ height is left between the inferior edge of the areola and the upper border of the elliptical marking.

All patients were operated upon under general anesthesia. One gram of the third generation cephalosporin was given at the induction of anesthesia.

\section{The surgical technique:}

The skin of the elliptical marking was deepithelialized (Fig. 2A). Then, an incision was performed at the IMF (lower border of deepithelialized ellipse) with the use of diathermy connected to a fine Colorado needle. Deepening of the incision was done and continued to reach the pectoral fascia. A retromammary pocket was created by dissection till the level of second intercostals space, the anterior axillary line laterally, and $2 \mathrm{~cm}$ from the sternal border medially. This pocket is created to accommodate the falling breast tissue (Fig. 2B).

At the upper edge of the deepithelialized dermoglandular segment, subcutaneous dissection was carried out for 2 to $3 \mathrm{~cm}$ distance (Fig. 3A). The dissection was performed to facilitate skin closure after enfolding of the dissected breast tissue and advancing it into the retromammary pocket. This dermoglandular segment was secured to the pectoral fascia at the level of third intercostal space by five sutures using (0) Ethilon suture material. Sutures were taken in the center and the periphery to tackle the breast segment to the pectoral fascia in a curvilinear manner (Fig. 3B). Subcutaneous closure was done with (2-0) PDS and subcuticular closure was done with (3-0) prolene.

\section{RESULTS}

Better projection was achieved by autoaugmentation in all cases. The average operative time was 60 to 70 minutes. The patients were discharged either on the same day or just stayed overnight. NAC vascularity was not affected. No recurrence was noticed in any of the cases during the follow-up. All patients were satisfied as regards shape, projection and the natural look of NAC position. The period of follow-up ranged from 6 months to 2 years, with the average of 12 months. Apart from two cases that developed partial unilateral wound disruption (central part), no serious complications took place. One of the two cases had hematoma that found its way through the disrupted wound. The other case had bilateral wound infection; however, disruption was only in one side. None of the two cases required secondary procedure. They were managed conservatively until spontaneous healing was achieved. Temporary 
hypoesthesia of nipples was reported in four cases that had intact sensation from the start. Fortunately, it was transient and recovery took place in 6 months. Fig. (4) shows a patient with bilateral bottoming out deformity following inferior pedicle breast reduction. The deformity was completely corrected. Fig. (5) shows preoperative and 6 month- postoperative photographs of a patient with bottoming out deformity of breasts after inferior pedicle reduction mammaplasty. Reduction was done 2 years prior to this procedure. The patient had periareolar and inverted T scars, and dog ears. Areolar scar was revised at the same sitting with no affection of NAC vascularity.
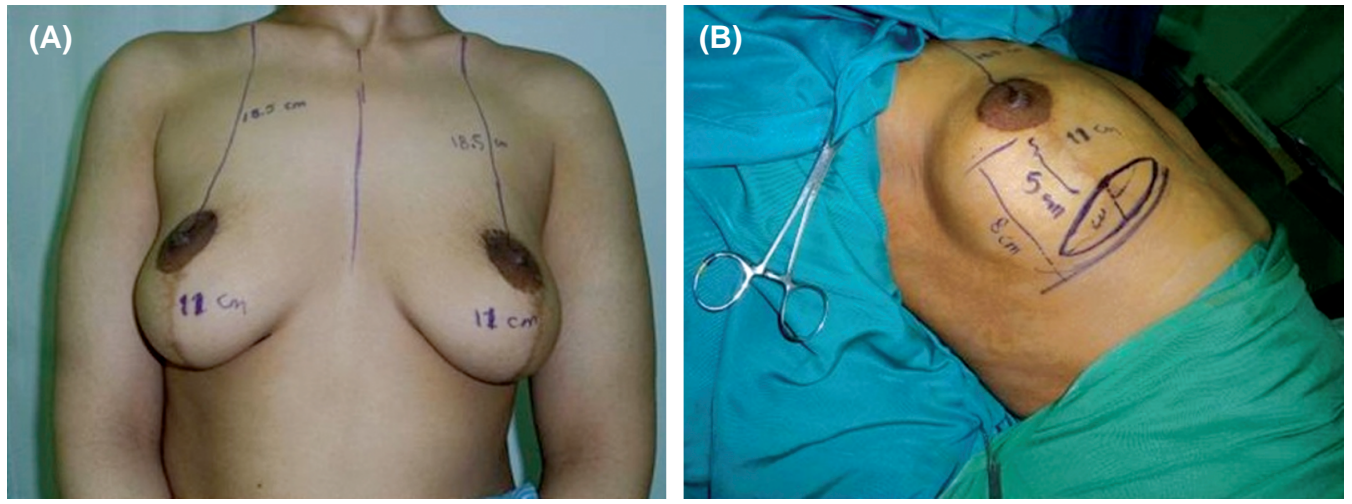

Fig. (1): (A) Markings of the distance between NAC and IMF, and NAC and mid-clavicle. (B) Marking of the ellipse centered on the transverse limb of inverted $\mathrm{T}$ scar.
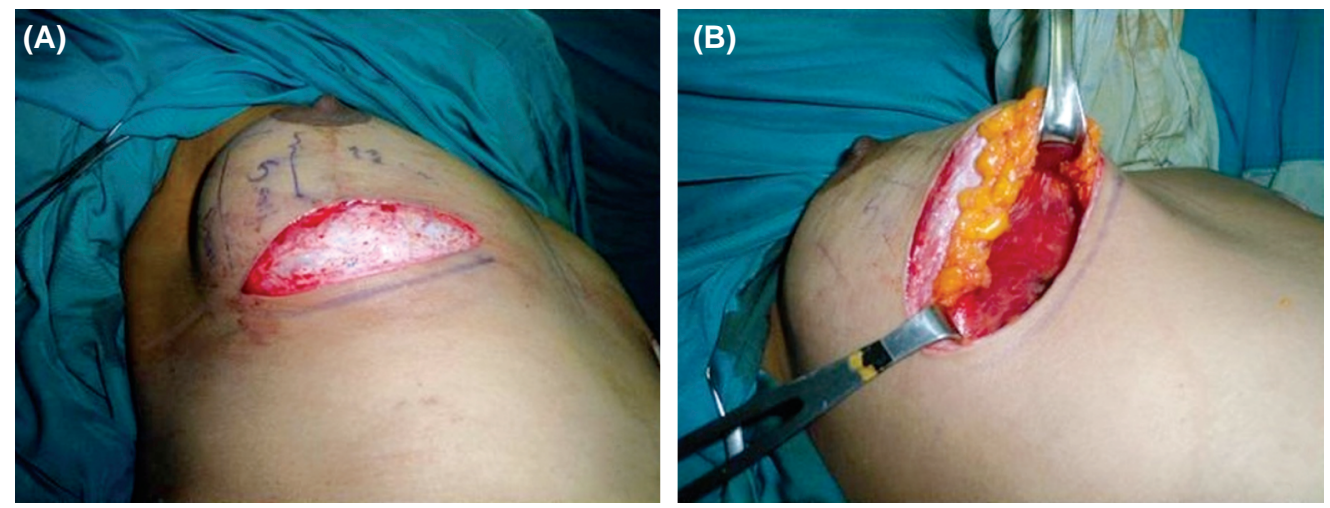

Fig. (2): (A) Deepithelialization of the marked lower breast segment. (B) Creation of retromammary pocket by dissection till the $2^{\text {nd. intercostal space. }}$
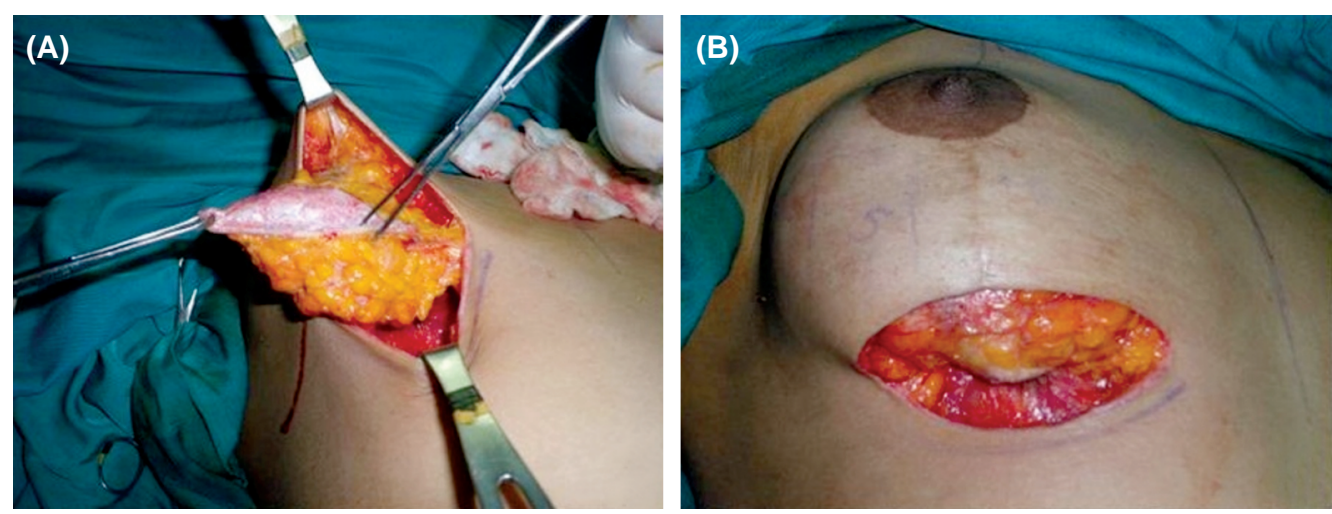

Fig. (3): (A) Subcutaneous dissection of the upper edge of the deepithelialized lower breast segment. (B) The demoglandular breast segment is enfolded and tucked to the pectoral fascia at the level of the $3^{\text {rd. intercostal space. }}$ 

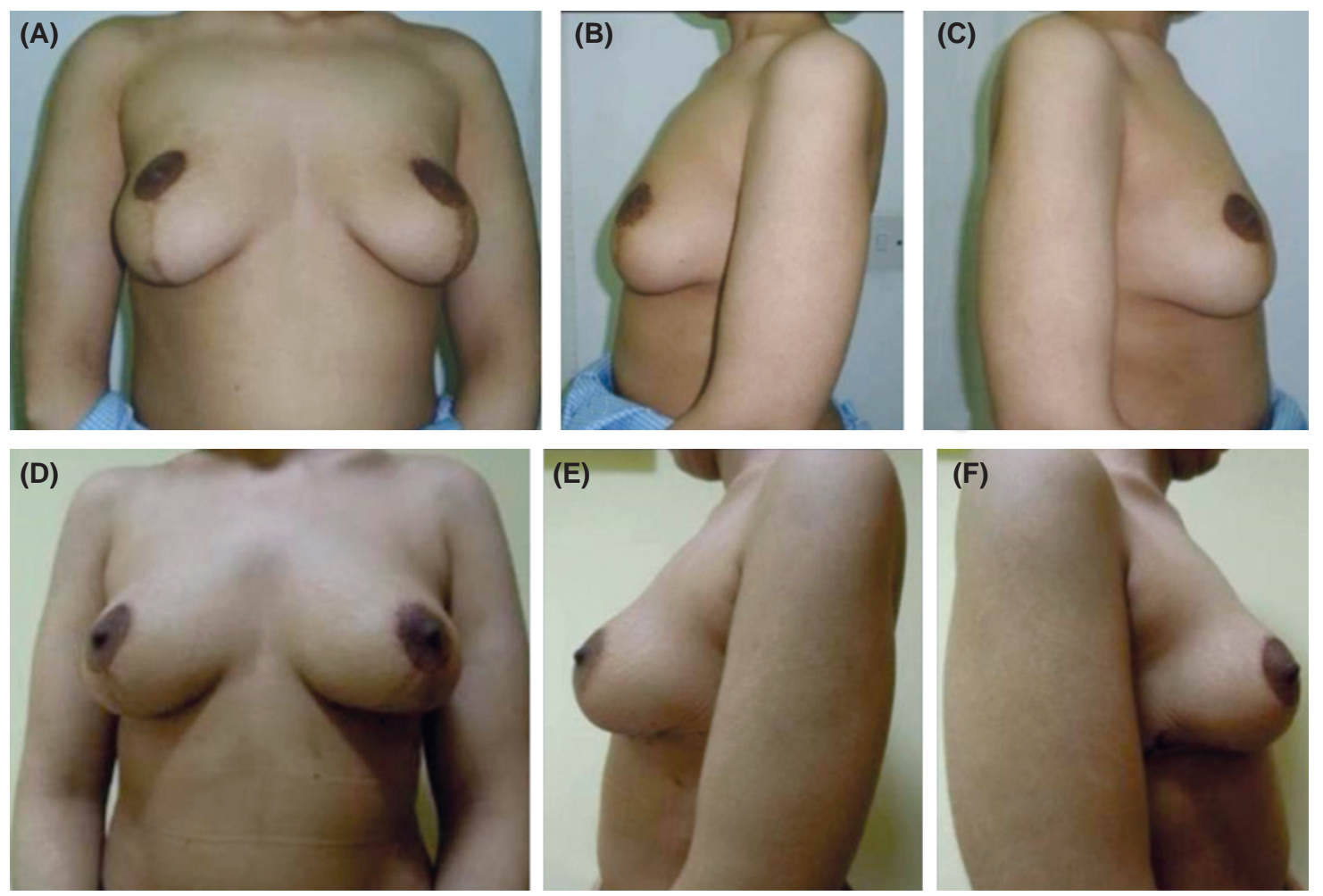

Fig. (4): A case with bottoming out deformity following inferior pedicle breast reduction. (A,B,C) Frontal and side views shows deformity and scars. (D,E,F) Postoperative correction of the deformity.
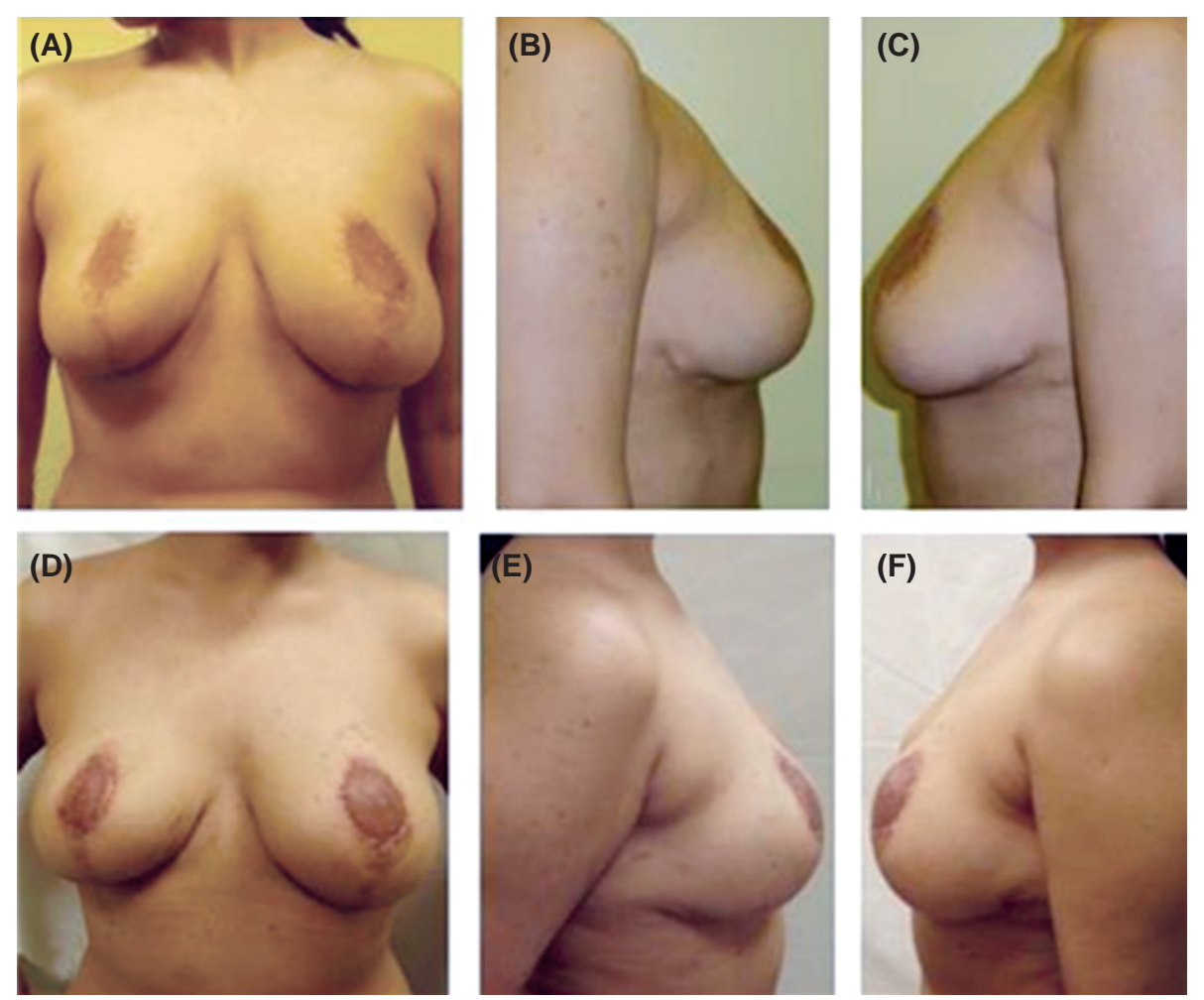

Fig. (5): 28 years old case with bottoming out deformity following inferior pedicle breast reduction. $(\mathrm{A}, \mathrm{B}, \mathrm{C})$ Frontal and side views of breasts showing deformity, scars and dog ears. (D, E, F) Postoperative correction of the deformity. 


\section{DISCUSSION}

In this article the authors addressed the correction of "bottoming out" deformity that occurs after inferior pedicle breast reduction. As what is also noticed in literature, there are two factors that contribute to its pathogenesis and characterizing that breast reduction technique. First, the main principle of the inferior pedicle with inverted $\mathrm{T}$ skin closure relying on the skin to maintain the breast shape (skin brassiere). The skin as a stretchable and expandable organ, it grows by stretch over time and so, it ultimately fails to keep the required support to maintain the breast shape. The second factor is that in the inferior pedicle technique there is lifting of the inferior breast tissue superiorly while basing it inferiorly, thus involving two opposing vectors. This makes the remaining breast tissue hanging fully exposed to the force of gravity, supported only by the expandable skin brassier which became more weakened by the inverted Tlong scar. The scars become increasingly broad adding more to the deformities. The presented new technique eliminated these two factors. The inferiorly based pedicle was totally divided at its base depending on neo-vascularization as if it is changed into a superior pedicle. The technique eliminated also the rising stretch force on the skin by internal suspension (fixation of dermal ellipse to pectoral fascia), and by using the dermal ellipse brassier instead of skin brassier. The external skin was no longer used to maintain the shape. It is only to be re-draped over the already shaped and lifted breast.

In Breast reduction surgery, the blood supply to the nipple-areola complex (NAC) would consist of the original pedicle along with the neovascularization from the surrounding breast tissue. Different authors $[16,32]$ had the concept of resection and highlighted the importance of the original pedicle especially if the nipple needs to be transposed. When the pedicle was unknown, they considered free nipple grafting.

We are concerned of the altered blood supply to the breast. The incision through the lower pole of breast was found to be safe, as none of our patients had NAC vascularity problem. Caution should be taken during retro- mammary dissection during pocket creation especially medially, to avoid interruption of the internal mammary perforators. We do not believe that transection of the pedicle, after neovascularisation, would compromise the NAC vascularity. However, we never corrected bottoming out before two years after the original reduction mammaplasty, to guarantee that volumetric and surface measurement changes have ceased and the vascularity has been established. This also eliminates obsession of using free nipple grafting.

Previous studies used tissue expansion/implants to increase the sternal notch nipple distance and push the high riding nipple down. So, augmentation would result as a secondary gain $[\mathbf{1 4 , 1 5}$. We aimed in this study to replace the breast tissue of the inferior pole back to its original place, thus, this technique is based on redistribution rather than excision of tissues. This would eliminate bottoming out and at the same time achieve auto-augmentation, with upper pole fullness and better projection. We disagree with previous studies [16,32] which aim to excise the inferior pole.

This presented technique used the already existed scars, unlike other techniques which reposition the NAC either by; adding scars superiorly in a reverse manner to bring it down [13], or by adding scars in the inferior pole [16,32]. We e revise the old scars to be utilized after deepithelialization for internal support. The concept of internal brassiere was also described by others using different methods [12,28-31]. We used the deepithelialized ellipse, which is rolled upwards to serve as dermal brassier. This carries the sagging pedicle upward in the desired new position. The rolled up pedicle is secured at the level of the third space using nonabsorbable suture material, thus keeping the achieved good shape and projection stable in the natural position.

\section{Conclusion:}

A novel technique is described for correction of bottoming out deformity following inferior pedicle reduction mammaplasty with inverted $\mathrm{T}$ technique. It depends on redistribution of tissues, not resection. The de-epithelialized portion including the old scar served as dermal internal support that carries the falling pedicle in an upward new position. This provided also auto-augmentation. The surgical technique has good outcome, with good and stable projection in the natural position. The technique is safe, and has the privilege of revising the old scars without adding any more scars.

\section{REFERENCES}

1- Ribeiro L., Accorsi A. Jr., Buss A. and Marcal-Pessoa M.: Creation and evolution of 30 years of the inferior pedicle in reduction mammaplasties. Plast. Reconstr. Surg., 110: 960-970, 2002.

2- Brink R: Management of true ptosis of the breast. Plast. Reconstr. Surg., 91: 657, 1993.

3- Chalekson C.P., Neumeister M.W., Zook E.G. and Russell R.C.: Outcome Analysis of Reduction Mammaplasty 
Using the Modified Robertson Technique, Plast. Reconstr. Surg., 110: 1, July 2002.

4- Small K.H., Tepper O.M., Unger J.G., Kumar N., Feldman D.L., Choi M. and Karp N.S.: Re-defining pseudoptosis from a 3D perspective after short scar-medial pedicle reduction mammaplasty, Journal of Plastic, Reconstructive \& Aesthetic Surgery, 63: 346e353, 2010.

5- Graf R. and Biggs T.M.: In Search of Better Shape in Mastopexy and Reduction Mammoplasty Discussion by Foad Nahai, Plast. Reconstr. Surg., 110: 1, July 2002.

6- Rohrich R.J., Gosman A.A., Brown S.A. and Reisch J.: Mastopexy Preferences: A Survey of Board-Certified Plastic Surgeons, Plast. Reconstr. Surg., 118: 7, Dec. 2006.

7- Davison S.P., Mesbahi A.N., Ducic I., Sarcia M., Dayan J. and Spear S.L.: The Versatility of the Superomedial Pedicle with Various Skin Reduction Patterns. Plast. Reconstr. Surg., 120: 6, Nov., 2007.

8- Ramirez O.M.: Reduction Mammaplasty with the "Owl" Incision and No Undermining, Plast. Reconstr. Surg., 109: 2, Feb. 2002.

9- Chun Y.S., Lalonde D.H. and May J.W. Jr.: Internal Pedicle Shaping to Improve Aesthetic Results in Reduction Mammaplasty. Plast. Reconstr. Surg., 119: 4, April 1, 2007.

10- Ceydeli A., Louis J., Yu J. and Ritter E.: Lateral Septal Preservation: A Technique to Improve Projection in Inferior Pedicle Reduction Mammaplasty by Preventing Lateral Displacement of the Pedicle. Plast. Reconstr. Surg., 120: 4, 1088-9, Sept 15, 2007.

11- Katsaros J., Harvey I. and Caplash Y.: The triplicated inferior pedicle: A new method for breast reduction and mastopexy Journal of Plastic, Reconstructive \& Aesthetic Surgery, Volume 63, Issue 7, Pages 1131-1135, July 2010.

12- Brown R.H., Izaddoost S. and Bullocks J.M.: Preventing the "Bottoming Out" and "Star-gazing" Phenomena in Inferior Pedicle Breast Reduction with an Acellular Dermal Matrix Internal Brassiere, Aesth. Plast. Surg., July 2010.

13- Millard D.R. Jr., Walter R.M. and Lesavoy M.A.: Secondary Correction of the Too-High Areola and Nipple After A Mammaplasty. Plast. Reconstr. Surg., 58: 5, Nov, 1976.

14- Raffel B.: Technique For Correction of Areola Misplacement With No New Scars. Plast. Reconstr. Surg., 88: 5, Nov., 1991.

15- Colwell A.S., May J.W. Jr. and Slavin S.A.: Lowering the Postoperative High-Riding Nipple Volume 120, Number 3, Plast. Reconstr. Surg. Sept., 1, 2007.

16- Hudson D.A. and Skoll P.J.: Repeat Reduction Mammaplasty. Plast. Reconstr. Surg., 104: 2, pp. 401-8, Aug., 1999.
17- Mathes S.J.: Plastic Surgery, 2nd ed., 6 (135), 2006.

18- Keck M., Kaye K., Thieme I., et al.: Vertical mammaplasty: postoperative changes, complications, and patient evaluation. Can. J. Plast. Surg., 15: 41-3, 2007.

19- de Araujo Cerqueira A.: Mammaplasty: breast fixation with dermoglandular mono upper pedicle flap under the pectoralis muscle. Aesthetic. Plast. Surg., 22: 276-283, 1998.

20- Qiao Q., Sun J., Liu C., Liu Z. and Zhao R.: Reduction mammaplasty and correction of ptosis: Dermal bra technique. Plast. Reconstr. Surg., 111: 1122-1130, 2003.

21- Baumeister R.G.: Curtain type combined pedicled reduction mammaplasty with internal suspension for extensive hypertrophic and ptotic breasts. Br. J. Plast. Surg., 56: 114-119, 2003

22- Caldeira A.M. and Lucas A.: Pectoralis major muscle flap: A new support approach to mammaplasty, personal technique. Aesthetic. Plast. Surg., 24: 58-70, 2000.

23- Da Silva G.: Mastopexy with dermal ribbon for supporting the breast and keeping it in shape. Plast. Reconstr .Surg., 34: 403-405, 1964

24- Lockwood T.: Reduction mammaplasty and mastopexy with superficial fascial system suspension. Plast. Reconstr. Surg., 103: 1411-1420, 1999.

25- Perez-Macias J.M.: Long-lasting evolution of ptosis control after reduction mammaplasty using the hammock technique. Aesthetic. Plast. Surg., 31: 266-274, 2007.

26- Widgerow A.D.: Breast reduction with inferior pedicle fascial suspension. Aesthetic. Plast. Surg., 29: 53-537, 2005.

27- Lewis G.K.: A method of mastopexy with fascia lata transplants. J. Int. Coll. Surg., 26: 346-353, 1956.

28- Goés J.C.S.: Periareolar mammaplasty: Double-skin technique with application of Polyglactine 910 mesh. Rev. Soc. Bras. Cir. Plast., 7: 1-3, 1992.

29- Goés J.C.S.: Periareolar mammaplasty: Double skin technique with application of polyglactine or mixed mesh. Plast. Reconstr. Surg., 97: 959-968, 1996.

30- Goés J.C.S.: Periareolar mastopexy and reduction with mesh support. Breast Surg., 51: 697-708, 1998.

31- Goés J.C.S.: Periareolar mastopexy: Double skin technique with mesh support. Aesthet. Surg. J., 3: 129-135, 2003.

32- Rohrich R.J., Thornton J.F. and Sorokin E.S.: Recurrent Mammary Hyperplasia: Current Concepts. Plast. Reconstr. Surg., 111: 1, Jan. 2003. 